\title{
Testing the Ideal Free Distribution Hypothesis: Moose Response to Changes in Habitat Amount
}

\author{
Abbie Stewart and Petr E. Komers \\ Department of Biological Sciences, University of Calgary, 2500 University Drive NW, \\ Calgary, AB, Canada T2N-1N4
}

Correspondence should be addressed to Abbie Stewart, abbie.stewart@mses.ca

Received 3 October 2011; Accepted 23 October 2011

Academic Editor: J. M. Witte

Copyright () 2012 A. Stewart and P. E. Komers. This is an open access article distributed under the Creative Commons Attribution License, which permits unrestricted use, distribution, and reproduction in any medium, provided the original work is properly cited.

\begin{abstract}
According to the ideal free distribution hypothesis, the density of organisms is expected to remain constant across a range of habitat availability, provided that organisms are ideal, selecting habitat patches that maximize resource access, and free, implying no constraints associated with patch choice. The influence of the amount of habitat on moose (Alces alces) pellet group density as an index of moose occurrence was assessed within the Foothills Natural Region, Alberta, Canada, using a binary patch-matrix approach. Fecal pellet density was compared across 45 sites representing a gradient in habitat amount. Pellet density in moose habitat increased in a linear or quadratic relationship with mean moose habitat patch size. Moose pellet density decreased faster thanwhat would be expected from a decrease in habitat amount alone. This change in pellet group density with habitat amount may be because one or both of the assumptions of the ideal free distribution hypothesis were violated.
\end{abstract}

\section{Introduction}

One of the basic tenets of ecology is to understand the distribution of organisms. The ideal free distribution (IFD) theory [1] relates the distribution of organisms to the availability of resources, specifically describing the equilibrium distribution between the amount of resources and the abundance of organisms. Assumptions associated with the IFD are that organisms are ideal, selecting patches that maximize resource access, and free, implying that there are no constraints associated with patch choice $[1,2]$. Within this framework, the IFD predicts that the number of individuals present is proportional to habitats or patches, with respect to the amount of resources available $[1,2]$. In doing so, the density of organisms is expected to remain constant per unit of habitat, regardless of the amount of habitat available or regardless of the habitat configuration, provided that access and quality of habitat remain constant.

Work with simulated landscapes has established predictions for the relationships between landscape configuration metrics, which measure the spatial arrangement of habitat, and the amount of habitat in the landscape [3-8]. Many of these relationships have been found to change nonlinearly with changes in amount of habitat cover, often with abrupt shifts or thresholds in the relationships. This suggests that there may be discontinuous changes in ecosystem functioning in relation to habitat loss [9], such that organism occurrence in the landscape may be affected by both habitat amount and fragmentation.

These conceptual frameworks lead to differing predicted relationships between species density and the amount of habitat. According to the IFD, if a species is only influenced by habitat amount (as opposed to configuration), then the species density in any given habitat unit will remain constant with changes in the habitat amount (Figure 1) [1, 10]. However, if the species is influenced by both habitat amount and landscape configuration, then the species density should not remain constant with changes in the habitat amount (Figure 1) [10]. This is because fragmentation, in particular patch isolation, would be expected to change access to habitat patches. If so, both assumptions of the IFD would potentially be violated because individuals would not be ideal due to a lack of information about the quality of distant patches, and 


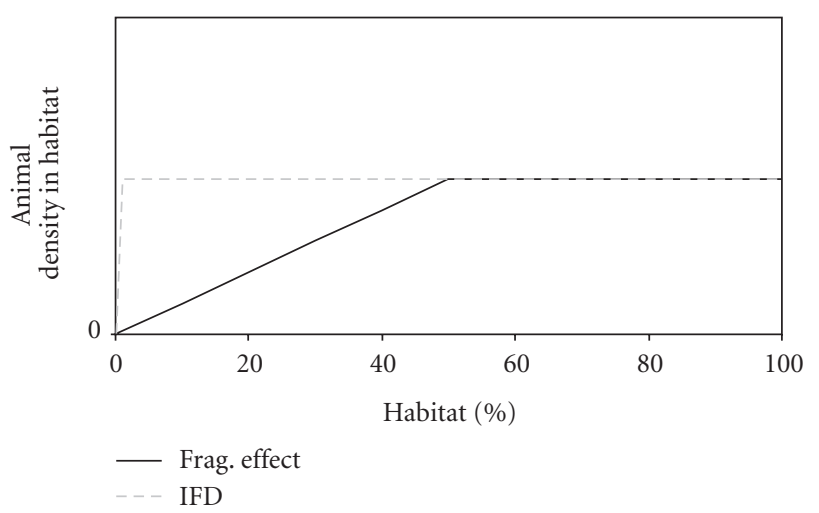

Figure 1: The ideal free distribution (IFD) hypothesis predicts that animal density in habitat is constant across a range of habitat amounts (gray dashed line). The influence of fragmentation (Frag.) on animal density results in a nonlinear response across a range of habitat amount (solid black line).
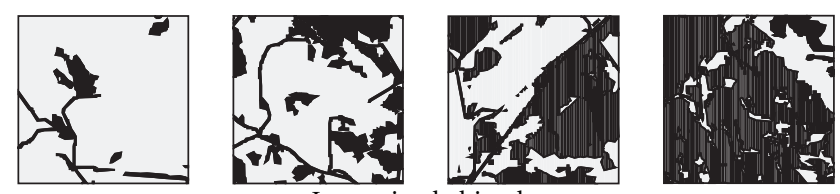

Low fragmentation Increasing habitat loss High fragmentation

FIGURE 2: Increasing habitat loss and resulting fragmentation of habitat (light gray) by nonhabitat (black) observed in the Foothills Natural Region of Alberta.

they would not be free to choose any given patch because of access constraints.

Fragmentation generally increases with decreasing habitat cover (Figure 2). At low amounts of habitat, it is expected that fragmentation effects are maximal because there are many isolated patches of habitat where access to patches may be constrained. At low amounts of habitat, patches are also, on average, smaller [3]. Animals may spend less time foraging in smaller patches because of reduced digestible energy and reduced overall energetic gain in these patches [11]. If species are responding to this habitat fragmentation, species density will be lower than that predicted by the IFD $[2,10]$. At high amounts of habitat, it is expected that fragmentation effects will be minimal because habitat is, on average, more contiguous.

Fragmentation can be measured with many different metrics but generally involves changes in the number of patches, edge amounts, and degree of isolation [10, 12-14]. As fragmentation increases, it is expected that the number of habitat patches increases and proximity of remaining habitat patches decreases. Edge density is expected to initially increase as fragmentation increases but subsequently decreases as entire patches of habitat are removed $[3,4]$.

Binary classification of the landscape is required for some statistical approaches addressing habitat loss and fragmentation issues, such as linear regression or correlation analyses. However, unfounded groupings of vegetation types into habitat versus nonhabitat categories should be avoided as they can lead to an undetermined heterogeneity in response variables [15]. Often landscapes are defined from a human perspective, resulting in human-induced disturbances being classified as nonhabitat [16]. Binary classifications must be backed by the investigation of not only how vegetation types are used relative to their availability but also how the different vegetation types influence the use of the other vegetation types in a landscape context. In other words, any given vegetation type may complement or supplement near by vegetation types, affecting their value as a resource $[17,18]$. Nevertheless, our previous analysis of moose habitat showed that, in our study area, shrubland was the habitat preferred by moose irrespective of complementation or supplementation by near by vegetation types [18].

We evaluated the ability of the IFD hypothesis to adequately explain moose (Alces alces) pellet density, or occurrence, across sites (landscapes) with varying mean moose habitat patch size. We use the term "habitat" to denote the vegetation type that is used significantly more than what would be expected from vegetation availability alone and has the highest observed proportion of pellet groups [18].

\section{Methods}

2.1. Study Area. The Alberta Foothills Natural Region (AFNR) covers about $25000 \mathrm{~km}^{2}$ along the eastern edge of the Rocky Mountains in Alberta, Canada $\left(53^{\circ} 13.847^{\prime} \mathrm{N} /\right.$ $\left.116^{\circ} 28.454^{\prime} \mathrm{W}\right)$. The boundaries of Alberta Natural Regions are defined according to vegetation, soils, and physiographic features, resulting in multiple regions, each with relatively consistent vegetation composition [19]. Vegetation in the AFNR consists mainly of closed-canopied coniferous, deciduous, and mixedwood forests. Grassland and shrubland vegetation is infrequently interspersed among forest stands $[20,21]$. Commercial timber management has been ongoing for over 50 years in this region [22]. Other human activity in this region includes mining, agriculture, urbanization, and oil and gas production. Only the AFNR was sampled in order to minimize the influence of any gradient in vegetation distribution across the study area (Figure 3 ).

2.2. Mapping Methods. Foothills Model Forest provided remote sensing vegetation information for this research [23]. Vegetation data were based on remote sensing imagery from 2 satellite sensor systems: Landsat Thematic Mapper (TM) and Moderate Resolution Imaging Spectrometer (MODIS). The remote sensing information, analyzed in 2003, provided a representation of land cover, crown closure, species composition attributes, and normalized difference vegetation index (NDVI) phenology. Remote sensing information, in combination with ground and helicopter surveys of $30 \times$ $30 \mathrm{~m}$ areas, resulted in a land cover classification with $81 \%$ accuracy $[24,24]$. Vegetation data were in raster format with $30 \mathrm{~m}$ pixel resolution. The original data classified pixels into 15 categories of which we identified shrubland as moose habitat in an earlier study [18]. For the purpose of this study, we identified the remaining vegetation categories as nonhabitat. During field surveys, vegetation information was 

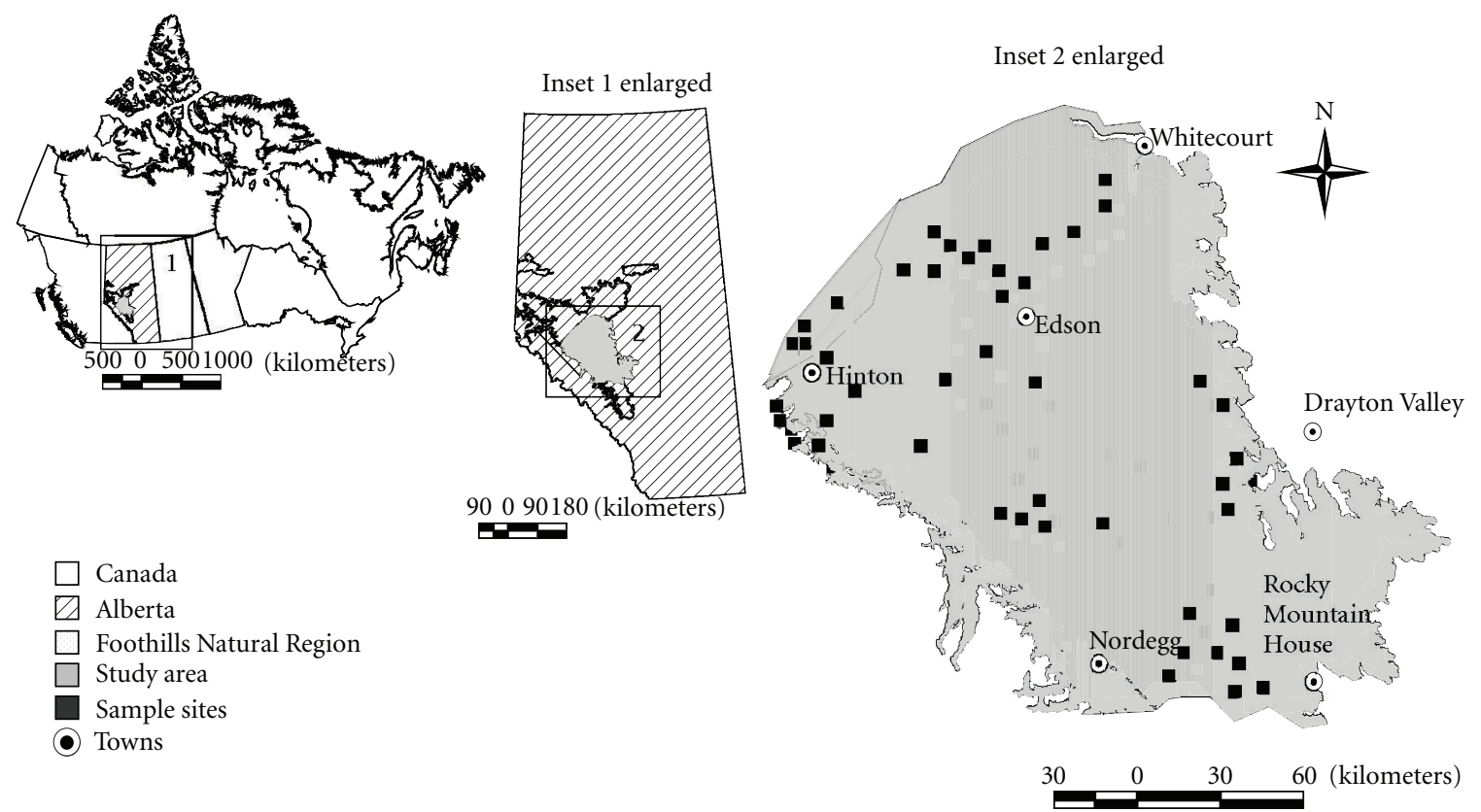

FIgURE 3: The study area falls within the AFNR, Alberta, Canada.

recorded and used to confirm or correct vegetation types in the map. Areas dominated by shrub species and with $<20 \%$ tree overstory were classified as shrubland, as were grassy areas with $\geq 30 \%$ shrub cover.

2.3. Sample Site Selection. Updated vegetation data were used concurrently with spatial (vector) data of Alberta's base features (see Table 1) to select sites for sampling (Alberta's base features (Base Mapping Data) were supplied through AltaLIS Ltd. [25]). Sites were $16 \mathrm{~km}^{2}(4 \times 4 \mathrm{~km})$, approximately the average moose fall and winter home range size [26-28].

Sites were selected to represent the variable amounts and combinations of the different vegetation types available in the study area. A shape file (geospatial vector data format) containing 1759 , randomly overlapping, $4 \times 4 \mathrm{~km}$ squares was created and placed over the study area vegetation layer, excluding facilities, towns, and villages (Table 1). Parks, reserves, and recreational areas were also avoided due to differences in land-use activities in these areas (Table 1). The area of each vegetation type falling within a $4 \times 4 \mathrm{~km}$ square was extracted from the vegetation map for sample site selection. First, sites were randomly selected from those available. Second, additional sites were selected such that the range of cover for each vegetation type was represented as completely as possible (i.e., gaps in the proportion of the $16 \mathrm{~km}^{2}$ area that each vegetation type made up were filled). Third, if a pair of sites overlapped, 1 of the sites was randomly removed. Configuration was not controlled for during site selection. Among 45 selected sites containing the data necessary for this analysis, the amount of shrubland (moose habitat according to Stewart et al. 2010) in the landscape ranged from $1 \%$ to $32 \%$ of the site.
Table 1: Province of Alberta Base Mapping Data themes and description.

\begin{tabular}{|c|c|c|}
\hline Theme & Description & $\begin{array}{l}\text { Last } \\
\text { modification }\end{array}$ \\
\hline Access polygon & $\begin{array}{l}\text { Polygonal representation of } \\
\text { all access and facility } \\
\text { features }\end{array}$ & 2002-03-22 \\
\hline Facility point & $\begin{array}{l}\text { Representation of all } \\
\text { facility points (except well } \\
\text { sites) in Alberta }\end{array}$ & 2003-05-20 \\
\hline Road arc & $\begin{array}{l}\text { Complete road network for } \\
\text { Alberta }\end{array}$ & 2003-05-20 \\
\hline Town polygon & $\begin{array}{l}\text { Polygonal representation of } \\
\text { towns as administered } \\
\text { under the authority of the } \\
\text { Municipal Government Act }\end{array}$ & 2001-06-01 \\
\hline Village polygon & $\begin{array}{l}\text { Polygonal representation of } \\
\text { villages as administered } \\
\text { under the authority of the } \\
\text { Municipal Government Act }\end{array}$ & 2001-06-01 \\
\hline $\begin{array}{l}\text { Forest rec. area } \\
\text { polygon }\end{array}$ & $\begin{array}{l}\text { Polygonal representation of } \\
\text { forest recreation areas } \\
\text { within Alberta, established } \\
\text { under the authority of the } \\
\text { Forest Act }\end{array}$ & 2001-11-28 \\
\hline $\begin{array}{l}\text { Indian res. } \\
\text { polygon }\end{array}$ & $\begin{array}{l}\text { Polygonal representation of } \\
\text { Indian reserves within } \\
\text { Alberta. }\end{array}$ & 2003-01-10 \\
\hline $\begin{array}{l}\text { Provincial park } \\
\text { polygon }\end{array}$ & $\begin{array}{l}\text { Polygonal representation of } \\
\text { provincial parks within } \\
\text { Alberta }\end{array}$ & 2001-08-10 \\
\hline
\end{tabular}

2.4. Pellet Group Survey. We gathered winter habitat use data on moose using fecal pellet group surveys in the spring 
of 2005 and 2006 (sites not resampled). The surveys were conducted prior to leaf-out (late April to early June) in both years to provide an index of moose distribution in winter. Our method ensured that new pellets (those lying above the previous years' leaf litter) were easily observed, while the older pellets were concealed by leaf litter [29, 30]. Spring fecal pellet group surveys provided moose pellet group density representing the cumulative depositions over the entire preceding winter period [29-31].

Pellet groups were counted within a $5.65 \mathrm{~m}$ radius circular plot $\left(100 \mathrm{~m}^{2}\right)$ [29]. Using a stratified random sampling procedure, we attempted to proportionally represent all vegetation types within each site using pellet group plots, excluding water and nonvegetated types. Plots were distributed a minimum of $200 \mathrm{~m}$ from each other and roads, preferably within a separate vegetation patch and separated by natural features, such as rivers. A total of 665 plots were sampled once each across 45 sites resulting in an average of approximately 15 plots per site.

Pellet group surveys were conducted by 6 different observers working independently. We trained all observers and allowed observers to independently sample plots once we obtained consistency between our pellet group counts. To maintain consistency, observers sampled at least 1 plot together per day to compare counts and species identification. Multiple observers were distributed within each site.

Within a plot, moose pellet groups were identified. A moose pellet group is defined as a minimum of 5 pellets, within 1 pellet's length of one another, and more than half of the pellets in the group must be within the sample plot to be counted $[32,33]$. Pellet groups occurring beneath fallen leaves or showing signs of decomposition (distorted shape and/or mold growth) were recorded as "old" and not included in analyses [34, 35].

2.4.1. Landscape Definition. To define the landscape in a species-specific binary manner, results of a previous mosaic analysis conducted on the same dataset were used [18]. According to a 3-step hierarchical regression analysis testing 5 habitat relationships (habitat amount, compensation, supplementation, complementation, and fragmentation), shrubland significantly contributed to increased moose pellet occurrence in the landscape and grassland-fragmented shrubland habitat. Thus, moose habitat was composed of shrubland habitat. This definition of moose habitat is used for analyses presented in this paper.

2.5. Hypothesis Testing. Moose pellet density was a continuous variable calculated for each site as the average number of pellet groups per hectare in shrubland. We assumed that moose occurrence was reflected in moose pellet density. Differences in pellet density between years was assessed with a Mann Whitney test using Systat v.11.00.01 software [36] to determine whether data from the 2 years were significantly heterogeneous, precluding data pooling. Moran's I test for spatial autocorrelation in residuals was used to test for spatial dependence in pellet density in shrubland among sites using ArcGIS v9.3.1 [37]. Spatial autocorrelation in the residuals results in over- or underestimation of observed values in some regions, when using regression analysis. This can result in unreliable inferences based on significance levels.

Based on the binary classification of the landscape, each $16 \mathrm{~km}^{2}$ site was exported from ArcView v3.1 in grid format. Class level metrics were calculated using FRAGSTATS v3.3 software [38]. The metrics that were calculated for shrubland habitat included mean patch size (MPS), number of patches (NP), edge density (ED), and area-weighted mean proximity (PROX; search radius $2000 \mathrm{~m}$ ). Mean patch size characterizes the distribution of area among patches. Number of patches is a simple measure of the degree of subdivision (i.e., fragmentation) of habitat. Edge density provides a measure of the edge of habitat, providing an indication of fragmentation when used in combination with the number of patches. The proximity index incorporates patch area into its calculation and is considered to be an effective measure of patch isolation [4], which is often associated with fragmentation [13]. Areaweighted means provide better estimates of central tendency [8].

Pellet density in shrubland was regressed against MPS of shrubland occurring in each site plus 2 covariates. Pellet density was $\log +1$ transformed to satisfy assumptions of normality and homoscedasticity. For this analysis, the linear model was not normal; however, a plot of residuals versus the predictor variable suggested the need for a curvilinear function to fit the data [39]. We have presented results for the linear model for completeness. All figures show back-transformed predicted response variables. The covariates included were length of linear features $(\mathrm{km})$ per site [25] and total hunter days. Moose hunting effort by the Wildlife Management Unit (WMU) was provided by the Alberta Sustainable Resource Development, Fish and Wildlife Division [40, 40]. These covariates were believed to be representative of a multitude of covariates that could potentially influence pellet density at the landscape scale (i.e., town and road proximity, level of human disturbance). Simple linear, quadratic polynomial, cubic polynomial, and piecewise [41] regression models with scaled independent variables were fit to the data using Systat software [36]. Model fit was assessed using the Akaike information criterion (AIC) [42]. AIC rewards goodness of fit and also includes a penalty for an increasing number of estimated parameters. The most parsimonious models are the ones with the fewest estimated parameters and an AICc $(\mathrm{n} / \mathrm{k}<40$; corrects for small sample sizes) value within 2 units of the smallest AICc.

Each of MPS, NP, ED, and PROX were regressed against the area of shrubland in the site to assess whether metrics followed the expected patterns based on simulations $[3,4]$. Moose pellet density in shrubland was regressed against each of NP, ED, and PROX plus 2 covariates: length of linear features $(\mathrm{km})$ per site and total hunter days. Simple linear, quadratic polynomial and cubic polynomial regression models with scaled independent variables were fit to the data using Systat software [36] and compared using AICc values [42]. Response variables were either square root, log, or $\log +1$ transformed to satisfy assumptions of normality and heteroscedasticity. For the analysis of ED in relation to shrubland area in the landscape, the quadratic and cubic 
TABLE 2: Regression results and AICc values for moose pellet group density in shrubland habitat versus MPS of shrubland habitat.

\begin{tabular}{lccccc}
\hline Model & Type & $P$ Value & $R^{2}$ & AICc & $\Delta$ AICc $(\mathrm{X}$-Smallest) \\
\hline Moose pellet density $=$ & Linear* & 0.042 & 0.18 & 74.18 & 0 \\
MPS + linear length + total & Quadratic* & 0.036 & 0.22 & 74.43 & 0.26 \\
hunter days $(n=45)$ & Cubic & 0.056 & 0.23 & 76.54 & 7.36 \\
& Piecewise & $\dagger$ & 0.18 & 79.67 & 5.49 \\
\hline
\end{tabular}

${ }^{*}$ Best models describing relationship; ${ }^{\ddagger}$ residuals not normal and suggest need for curvilinear model; ${ }^{\dagger}$ no breakpoint found.

TABLE 3: Regression results and AICc values for moose pellet group density in shrubland habitat versus area of shrubland habitat.

\begin{tabular}{|c|c|c|c|c|c|}
\hline Model & Type & $P$ Value & $R^{2}$ & $\mathrm{AICc}$ & $\Delta \mathrm{AICc}(\mathrm{X}-$ Smallest $)$ \\
\hline \multirow{4}{*}{$\begin{array}{l}\text { Moose pellet density = area } \\
\text { of shrubland in landscape } \\
+ \text { linear length }+ \text { total } \\
\text { hunter days }(n=45)\end{array}$} & Linear*‡ & 0.037 & 0.19 & 73.86 & 0 \\
\hline & Quadratic* & 0.045 & 0.21 & 75.01 & 1.15 \\
\hline & Cubic & 0.049 & 0.24 & 76.159 & 2.299 \\
\hline & Piecewise $^{\dagger}$ & - & 0.19 & 76.54 & 2.68 \\
\hline
\end{tabular}

${ }^{*}$ Best models describing relationship; ${ }^{\ddagger}$ residuals not normal and suggest need for curvilinear model; ${ }^{\dagger}$ no breakpoint found.

models were not normal. However, small departures from normality are unlikely to have serious consequences, and plots of the residuals against their expected values under normality suggested that the distribution of the error terms did not depart substantially from a normal distribution [39].

An F-test was performed to test the equality of variance in pellet density between sites containing small mean patch size of shrubland (0-10 ha) and sites with large mean patch size of shrubland (10.1-21.5 ha).

Pellet density in shrubland was regressed against the area of shrubland occurring in each site plus 2 covariates. Pellet density was $\log +1$ transformed to satisfy assumptions of normality and homoscedasticity. For this analysis, the linear model was not normal but the data suggest the need for a curvilinear function to fit the data [39].

\section{Results}

Residuals from the simple linear model (pellet density in shrubland) were not significantly spatially autocorrelated among sites (Moran's I: $-0.06, P=0.70, n=45$ ). There was no significant difference in pellet density in shrubland between years (Mann Whitney, $P=0.60, n=45$ ). Therefore, data from 2005 and 2006 were pooled, and the data were spatially independent.

The relationship between moose pellet density and MPS of shrubland was described by either a simple linear or quadratic polynomial relationship, according to AICc values, both showing an increase in density with increasing shrubland patch size (Table 2, Figure 4).

Although the average moose pellet density is lowest at low patch sizes, the variance in moose pellet density in sites with low MPS of moose habitat was significantly higher than the variance in sites with high MPS of moose habitat (F-test, $d f=36,7, P=0.001)$. Moreover, the moose pellet density in shrubland increased with the total amount of moose habitat in that site, irrespective of landscape configuration (Table 3 ).

The quadratic polynomial model was the best model for describing the relationship between ED of shrubland

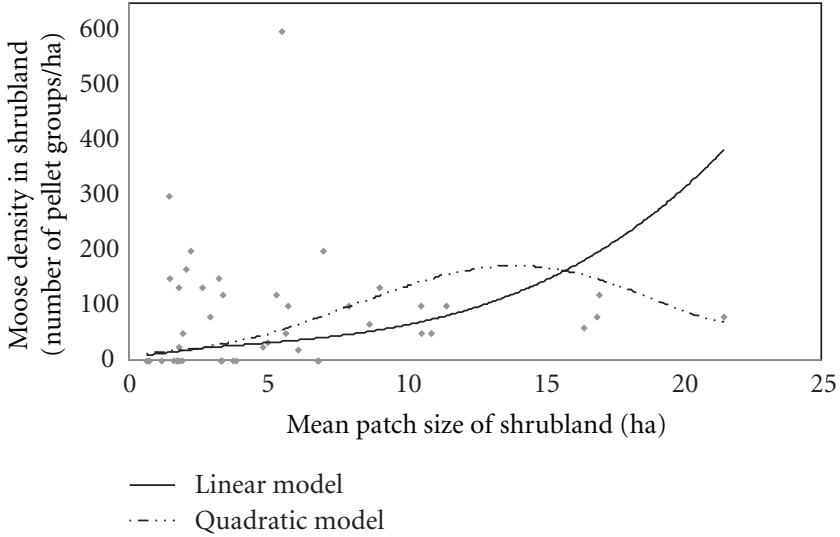

FIGURE 4: Moose pellet group density in shrubland habitat increases as mean moose habitat patch size increases in the landscape.

and the total amount of shrubland. The quadratic and cubic polynomial models were both potential candidates for describing the relationship between PROX of shrubland and the total amount of shrubland. The cubic polynomial model was the best model for describing the relationship between mean moose habitat patch size and the total amount of shrubland (Table 4, Figure 5). No significant relationship was found between the NP of shrubland and the total amount of shrubland.

No significant relationships were found between moose pellet density in shrubland and the NP, ED, or PROX of shrubland.

\section{Discussion}

Our results indicate that moose pellet density decreased with decreasing size of habitat patches. This suggests that moose occurrence was not constant across a range in habitat or patch size as would be predicted by the IFD. One assumption of the IFD hypothesis is that there is no cost associated with 
TABLE 4: Regression results and AICc values for shrubland class metrics versus the area of shrubland habitat.

\begin{tabular}{|c|c|c|c|c|c|}
\hline Class Metric & Type & $P$ Value & $R^{2}$ & $\mathrm{AICc}$ & $\Delta \mathrm{AICc}(\mathrm{X}-$ Smallest $)$ \\
\hline \multirow{3}{*}{$\begin{array}{l}\mathrm{ED}=\text { area of shrubland in } \\
\text { landscape }(n=45)\end{array}$} & Linear & $<0.0001$ & 0.80 & -47.46 & 22.28 \\
\hline & Quadratic $^{* \dagger}$ & $<0.0001$ & 0.88 & -69.743 & 0 \\
\hline & Cubict & $<0.0001$ & 0.89 & -67.36 & 2.38 \\
\hline \multirow{3}{*}{$\begin{array}{l}\text { PROX = area of shrubland } \\
\text { in landscape }(n=45)\end{array}$} & Linear & $<0.0001$ & 0.51 & 53.74 & 5.62 \\
\hline & Quadratic* & $<0.0001$ & 0.59 & 45.01 & 0.05 \\
\hline & Cubic* & $<0.0001$ & 0.62 & 42.49 & 0 \\
\hline \multirow{3}{*}{$\begin{array}{l}\text { MPS = area of shrubland in } \\
\text { landscape }(n=45)\end{array}$} & Linear & $<0.0001$ & 0.62 & -46.21 & 6.21 \\
\hline & Quadratic & $<0.0001$ & 0.67 & -50.15 & 2.27 \\
\hline & Cubic* & $<0.0001$ & 0.70 & -52.43 & 0 \\
\hline
\end{tabular}

${ }^{*}$ Best models describing relationship; ${ }^{\dagger}$ residuals not normal, departure not substantial.

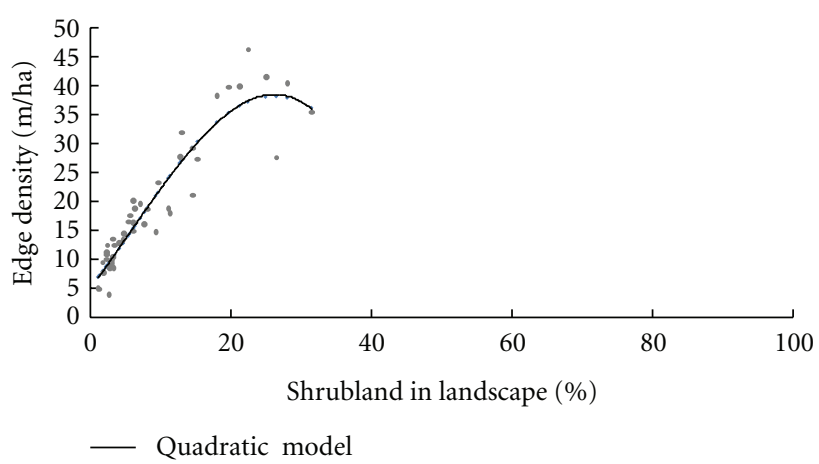

(a)

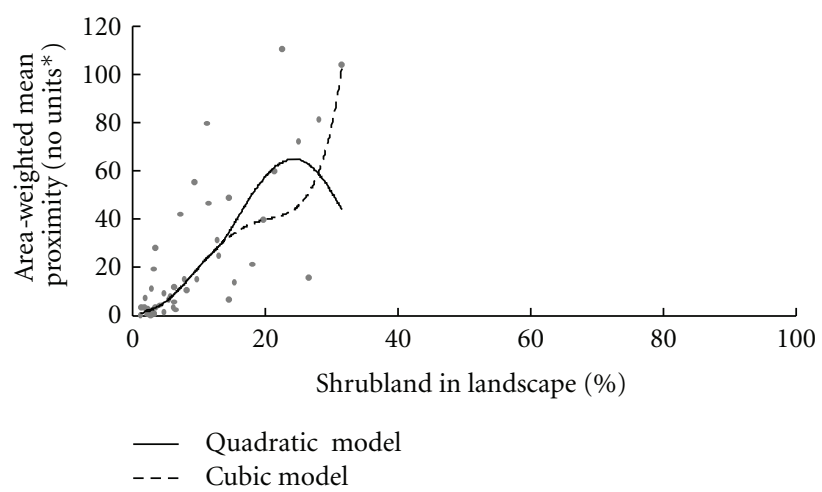

(b)

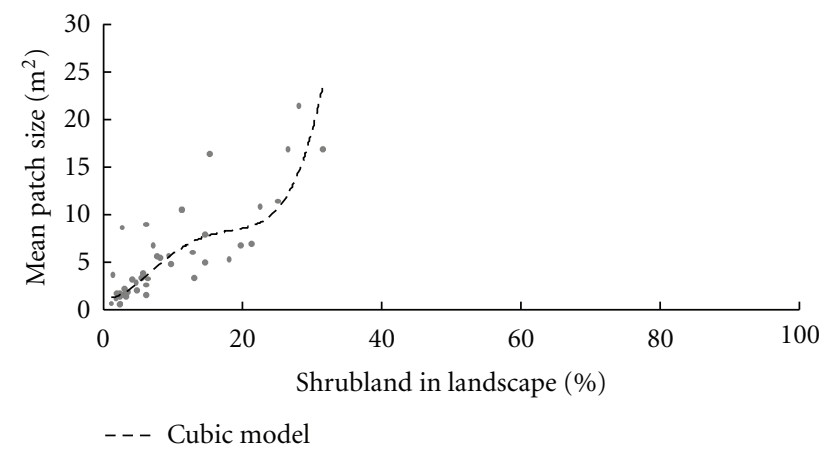

(c)

FIGURE 5: ED, PROX, and MPS of shrubland versus total area of shrubland habitat in the landscape.

movement between patches. However, when the distance between patches of habitat in the landscape increases due to fragmentation of the landscape, one might expect associated access constraints for individuals. Decreasing proximity of habitat patches may indicate that this assumption of no cost for movement between patches was violated in this study (Figure 5). Measuring ED can indicate if habitat has become divided into more patches or if entire patches are being removed from a landscape. Edge density is expected to initially increase as fragmentation increases but subsequently decrease as entire patches of habitat are removed. It appears that our results support this relationship (Figure 5). The class level metrics used in our study, except NP, largely corresponded to expected relationships with the amount of habitat in the landscape, as outlined in Hargis et al. [4] (1998) and Gustafson and Parker [3] (1992) who used artificial landscapes. Overall, habitat fragmentation increased with decreasing habitat amount.

Moose pellet density in habitat appeared to be affected by the configuration of habitat in the landscape. High moose pellet density was associated with larger patches of habitat (Figure 4). Our results also show that, while average density increased with patch size, the variance around the average decreased. We hypothesize that the larger variability in moose occurrence within small habitat patches may be due to variability in access to isolated patches and information 
available to a moose about their quality. The observation that, on average, moose pellet density was higher in large patches may be seen as support for the marginal value theorem used to predict patch-leaving times. The marginal value theorem states that animals are likely to remain longer on more profitable patches or those with high resource availability, as long as forage intake remains average or above the average intake rate over all available patches [43]. Our finding, however, that some small patches had a low or zero density of moose pellets while a few had a high density suggests that inadequate information about patch quality, such as forage productivity or composition, and possible access constraints between small patches may complicate patch leaving decisions. In order to understand what additional factors may influence moose occurrence, future research should consider what is driving patch leaving decisions.

Understanding the density-area relationship for individual species can help increase the effectiveness of wildlife conservation strategies [44]. Conservation strategies need to be informed by the fact that the IFD may not adequately predict species occurrence. With a disproportionate decrease in the use of habitat in relation to habitat removal, conservation action may need to be intensified earlier than expected in order to mitigate the impacts of habitat loss on species abundance.

\section{Acknowledgments}

The authors thank Mary Reid, Darren Bender, Elizabeth Dickson, and Shelley Alexander for providing advice and thoughtful reviews of this paper. They also thank Michelle Dubois and Kate Overmoe for their assistance in data collection. This research was funded by AMEC, MSES, ASRPW, and the University of Calgary. Vegetation maps were provided by the Foothills Model Forest. GIS guidance was provided by Zoran Stanojevic.

\section{References}

[1] S. D. Fretwell and H. L. Lucas, "On territorial behavior and other factors influencing habitat distribution in birds," Acta Biotheoretica, vol. 19, no. 1, pp. 16-36, 1970.

[2] C. Bernstein, A. Kacelnik, and J. R. Krebs, "Individual decisions and the distribution of predators in a patchy environment. II. The influence of travel costs and structure of the environment," Journal of Animal Ecology, vol. 60, no. 1, pp. 205-225, 1991.

[3] E. J. Gustafson and G. R. Parker, "Relationships between landcover proportion and indices of landscape spatial pattern," Landscape Ecology, vol. 7, no. 2, pp. 101-110, 1992.

[4] C. D. Hargis, J. A. Bissonette, and J. L. David, "The behavior of landscape metrics commonly used in the study of habitat fragmentation," Landscape Ecology, vol. 13, no. 3, pp. 167-186, 1998.

[5] L. Tischendorf, "Can landscape indices predict ecological processes consistently?" Landscape Ecology, vol. 16, no. 3, pp. 235-254, 2001.

[6] M. C. Neel, K. McGarigal, and S. A. Cushman, "Behavior of class-level landscape metrics across gradients of class aggregation and area," Landscape Ecology, vol. 19, no. 4, pp. 435-455, 2004.

[7] J. Bascompte and R. V. Solé, "Habitat fragmentation and extinction thresholds in spatially explicit models," Journal of Animal Ecology, vol. 65, no. 4, pp. 465-473, 1996.

[8] E. J. Gustafson, "Quantifying landscape spatial pattern: what is the state of the art?" Ecosystems, vol. 1, no. 2, pp. 143-156, 1998.

[9] Wu Jianguo and O. L. Loucks, "From balance of nature to hierarchical patch dynamics: a paradigm shift in ecology," Quarterly Review of Biology, vol. 70, no. 4, pp. 439-466, 1996.

[10] H. Andren, "Effects of habitat fragmentation on birds and mammals in landscapes with different proportions of suitable habitat: a review," Oikos, vol. 71, no. 3, pp. 355-366, 1994.

[11] L. A. Shipley and D. E. Spalinger, "Influence of size and density of browse patches on intake rates and foraging decisions of young moose and white-tailed deer," Oecologia, vol. 104, no. 1, pp. 112-121, 1995.

[12] J. Bogaert, P. Van Hecke, D. Salvador-Van Eysenrode, and I. Impens, "Landscape fragmentation assessment using a single measure," Wildlife Society Bulletin, vol. 28, no. 4, pp. 875-881, 2000.

[13] J. M. Lord and D. A. Norton, "Scale and the spatial concept of fragmentation," Conservation Biology, vol. 4, no. 2, pp. 197202, 1990

[14] P. Opdam, R. Foppen, R. Reijnen, and A. Schotman, "The landscape ecological approach in bird conservation: integrating the metapopulation concept into spatial planning," Ibis, vol. 137, no. 1, pp. 139-146, 1995.

[15] A. Mysterud and R. A. Ims, "Functional responses in habitat use: availability influences relative use in trade-off situations," Ecology, vol. 79, no. 4, pp. 1435-1441, 1998.

[16] Y. Haila, "A conceptual genealogy of fragmentation research: from island biogeography to landscape ecology," Ecological Applications, vol. 12, no. 2, pp. 321-334, 2002.

[17] L. Brotons, A. Wolff, G. Paulus, and J. L. Martin, "Effect of adjacent agricultural habitat on the distribution of passerines in natural grasslands," Biological Conservation, vol. 124, no. 3 , pp. 407-414, 2005.

[18] A. Stewart, P. E. Komers, and D. J. Bender, "Assessing landscape relationships for habitat generalists," Ecoscience, vol. 17, no. 1, pp. 28-36, 2010.

[19] D. J. P. W. W. Downing, Natural Regions and Subregions of Alberta, Publication No. T/852, Natural Regions Committee, Government of Alberta, 2006.

[20] W. L. Strong, Ecoregions and Ecodistricts of Alberta, lberta Forestry, Lands and Wildlife, Edmonton, Canada, 1992.

[21] J. D. Beckingham, I. G. W. Corns, and J. H. Archibald, Field Guide to Ecosites of West-Central Alberta, Natural Resources Canada, Canadian Forest Service, Northwest Region, Northern Forestry Centre, Edmonton, Canada, 1996.

[22] P. J. Murphy, R. Udell, R. E. Stevenson, and R. Bott, The Hinton Forest 1955-2000. A Case Study in Adaptive Forest Management, The Weldwood-Hinton Story, Foothills Model Forest, 2002.

[23] Foothills Model Forest, "Foothills Model Forest: research growing into practice," 2007, http://www.fmf.ca/.

[24] S. E. Nielsen, R. H. M. Munro, and M. S. Boyce, "Modeling grizzly bear activity by time of day and habitat in westcentral Alberta," in Foothills Model Forest Grizzly Bear Research Program 2005 Annual Report, G. Stenhouse and K. Graham, Eds., Hinton, Alberta, Canada, 2006.

[25] AltaLIS, "AltaLIS: Digital Mapping for Alberta," 2007, http://altalis.com/. 
[26] C. Laurian, J. P. Ouellet, R. Courtois, L. Breton, and S. StOnge, "Effects of intensive harvesting on moose reproduction," Journal of Applied Ecology, vol. 37, no. 3, pp. 515-531, 2000.

[27] W. R. Mytton and L. B. Keith, "Dynamics of moose populations near Rochester, Alberta, 1975-1978," Canadian Field Naturalist, vol. 95, pp. 39-49, 1981.

[28] F. Van Dyke, B. L. Probert, and G. M. Van Beek, "Moose home range fidelity and core area characteristics in south-central Montana," Alces, vol. 31, pp. 91-104, 1995.

[29] D. J. Neff, "The pellet-group count technique for big game trend, census, and distribution: a review," Journal of Wildlife Management, vol. 32, no. 3, pp. 597-614, 1968.

[30] D. J. Augustine and L. E. Frelich, "Effects of white-tailed deer on populations of an understory forb in fragmented deciduous forests," Conservation Biology, vol. 12, no. 5, pp. 995-1004, 1998.

[31] F. W. Weckerly and M. A. Ricca, "Using presence of sign to measure habitats used by Roosevelt elk," Wildlife Society Bulletin, vol. 28, no. 1, pp. 146-153, 2000.

[32] L. L. Strong and D. J. Freddy, "Number of pellets per mule deer defecation," Journal of Wildlife Management, vol. 43, no. 2, pp. 563-564, 1979.

[33] S. Härkönen and R. Heikkilä, "Use of pellet group counts in determining density and habitat use of moose Alces alces in Finland," Wildlife Biology, vol. 5, no. 4, pp. 233-239, 1999.

[34] A. L. Cairns and E. S. Telfer, "Habitat use by 4 sympatric ungulates in boreal mixedwood forest," Journal of Wildlife Management, vol. 44, no. 4, pp. 849-857, 1980.

[35] A. W. Franzman, J. L. Oldemeyer, P. D. Arneson, and R. K. Seemel, "Pellet-group count evaluation for census and habitat use of Alaskan moose," in Proceedings of the North American Moose Conference and Workshop, vol. 12, pp. 127-142, 1976.

[36] Systat Software Inc., "Systat 11.00," no. release 11.00, Systat Software Inc, 2004.

[37] Environmental Systems Research Institute, "ArcGIS v.9.3.1," no. 9.3.1, Redlands, Calif, USA, 2009.

[38] K. McGarigal and B. J. Marks, "FRAGSTATS: spatial pattern analysis program for quantifying landscape structure," USDA Forest Service General Technical Report in Forest Sciences, vol. PNW-351, 1995.

[39] J. Neter, M. H. Kutner, C. J. Nachtsheim, and W. Wasserman, Applied Linear Statistical Models, WCB McGraw-Hill, Boston, Mass, USA, 1996.

[40] ASRD, "Hunting in Alberta," 2007, http://www.srd.gov.ab.ca/.

[41] J. D. Toms and M. L. Lesperance, "Piecewise regression: a tool for identifying ecological thresholds," Ecology, vol. 84, no. 8, pp. 2034-2041, 2003.

[42] K. P. Burnham and D. R. Anderson, Model Selection and Inference: A Practical Information-Theoretic Approach, Springer, New York, NY, USA, 1998.

[43] K. R. Searle, N. T. Hobbs, and L. A. Shipley, "Should I stay or should I go? Patch departure decisions by herbivores at multiple scales," Oikos, vol. 111, no. 3, pp. 417-424, 2005.

[44] S. F. Matter, "The importance of the relationship between population density and habitat area," Oikos, vol. 89, no. 3, pp. 613-619, 2000. 

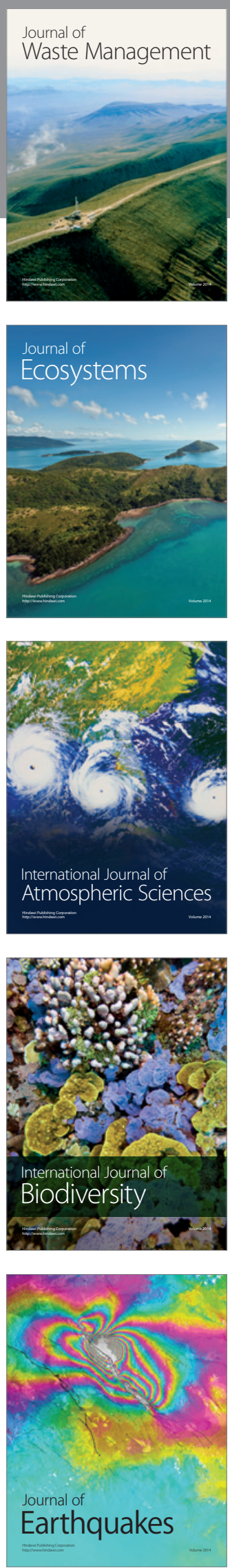
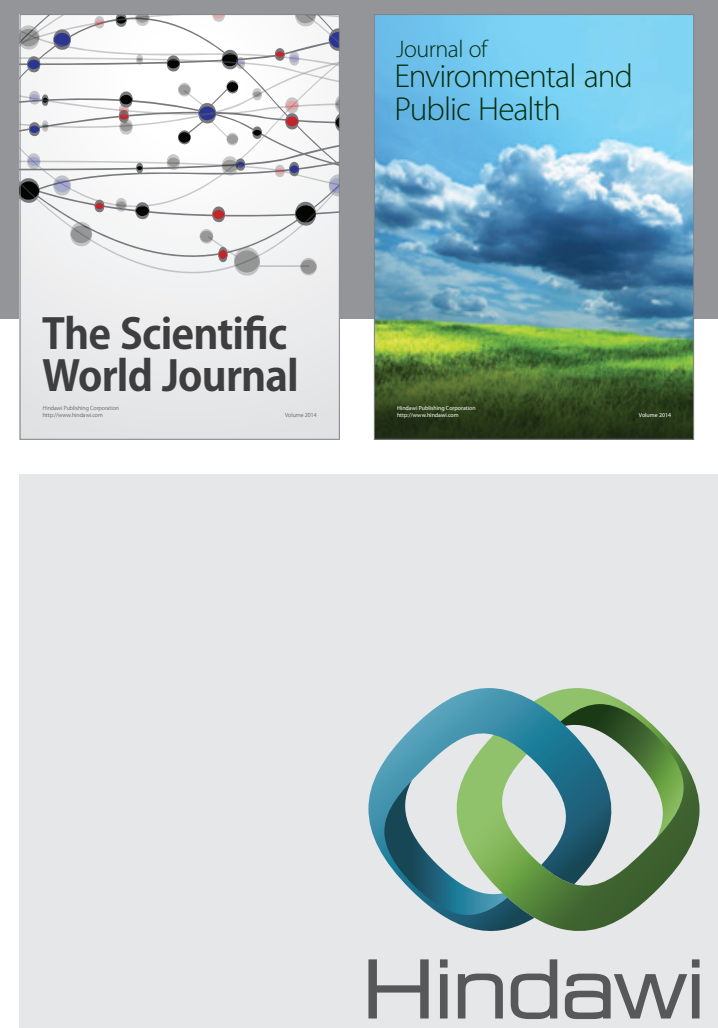

Submit your manuscripts at

http://www.hindawi.com
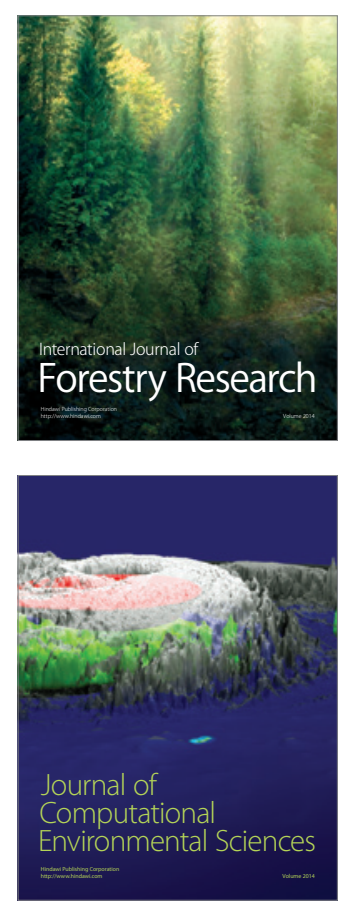
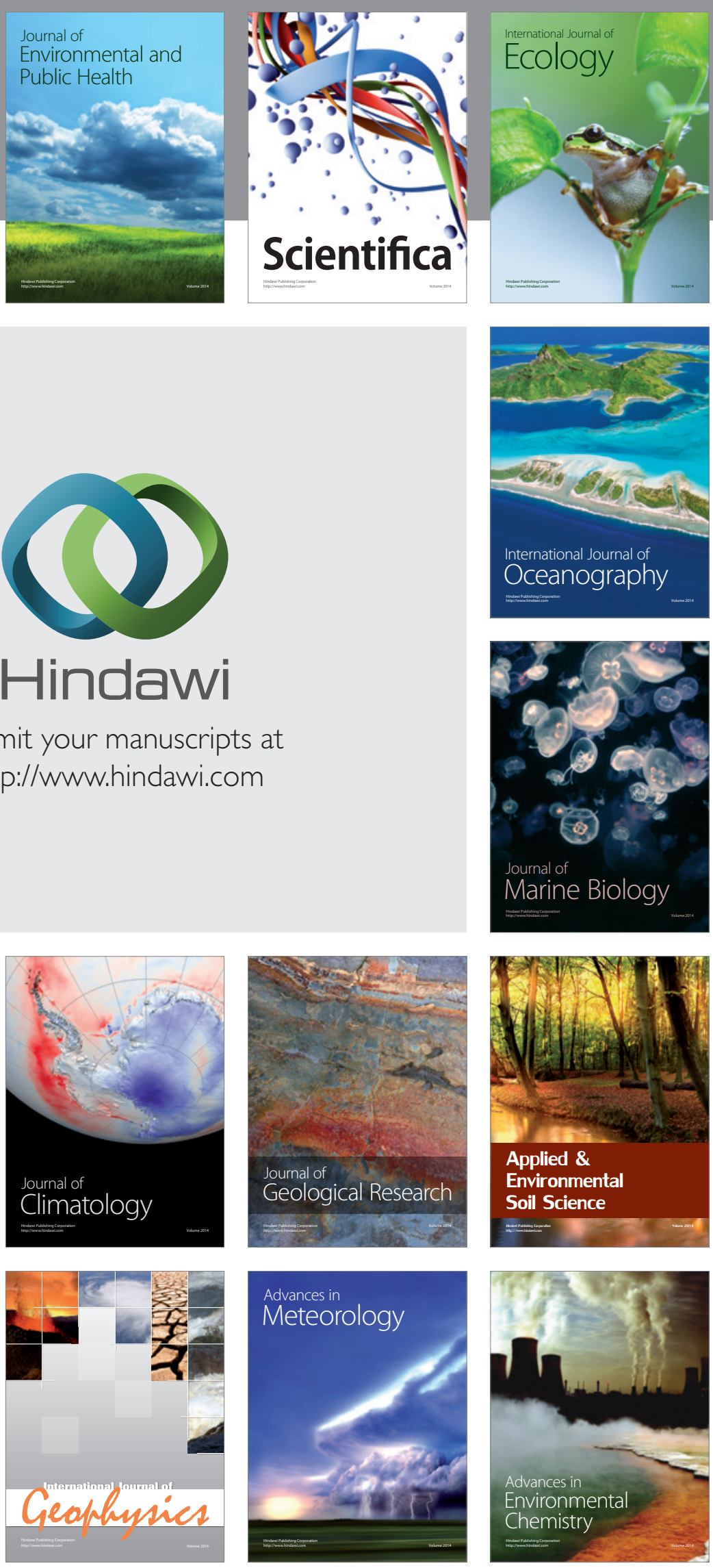